\title{
Solusi Permasalahan Perzakatan di BAZNAS dengan Metode ANP: Studi tentang Implementasi Zakat Core Principles
}

\author{
Lukman Hamdani ${ }^{*}$, M. Yasir Nasution ${ }^{2}$ dan Muslim Marpaung ${ }^{3}$ \\ ${ }^{1}$ Ekonomi Syariah, Universitas Islam Negeri Sumatera Utara \\ ${ }^{2}$ Pascasarjana, Universitas Islam Negeri Sumatera Utara \\ ${ }^{3}$ Perbankan Syariah, Politeknik Negeri Medan
}

Masuk: 2 Mei 2019, Diterima: 1 Agustus 2019, Terbit: 5 Agustus 2019

\begin{abstract}
The Zakat Core Principles (ZCP) is the core principles of zakat which cover 18 aspects related to the management of zakat. This study aims to obtain empirical evidence about solutions to Zakat Problems in BAZNAS (National Zakat Agency) and implementation of ZCP. This study uses qualitative methods with ANP (Analytic Network Process) analysis tool. The results of this study explain the most priority problems that need immediate response is in the form of lack of socialization and education about ZCP, BAZNAS must be more accountable and transparent in every report, and BAZNAS must have sharia control. The most priority strategy is the substance of ZCP that must be implemented, BAZNAS must be formally and financially independent as well as continuous socialization and education at BAZNAS. The conclusion is that the ZCP has not been implemented as a whole, especially in BAZNAS at the regional level.
\end{abstract}

Keywords: zakat core principles; analytic network process; solutions; National Zakat Agency

\begin{abstract}
Abstrak
Zakat Core Principles (ZCP) adalah prinsip-prinsip inti zakat yg mencakup 18 aspek terkait pengelolaan zakat. Penelitian ini bertujuan untuk mendapatkan bukti empiris mengenai Solusi Permasalahan Perzakatan di BAZNAS (Badan Amil Zakat Nasional) dan implementasi tentang ZCP. Penelitian ini menggunakan metode kualitatif dengan alat analisis ANP (Analytic Network Process). Hasil penelitian ini memaparkan bahwa masalah yang paling prioritas yang perlu segera mendapatkan respon adalah berupa kurangnya sosialisasi dan edukasi tentang ZCP, BAZNAS harus lebih akuntabel dan transparan di setiap laporan, serta BAZNAS harus ada yang mengontrol secara syariah. Strategi yang paling prioritas adalah substansi ZCP yang harus diimplementasikan, BAZNAS harus mandiri secara formal dan finansial serta sosialisasi dan edukasi yang terus menerus di BAZNAS. Kesimpulannya adalah bahwa ZCP belum diterapkan secara menyeluruh terutama di BAZNAS tingkat daerah.
\end{abstract}

Kata Kunci: prinsip-prinsip inti zakat; analytic network process; solusi; BAZNAS

\footnotetext{
* Corresponding author 


\section{PENDAHULUAN}

Zakat merupakan salah satu item terpenting dalam filantropi Islam. Sebagai rukun Islam ketiga, zakat wajib dilaksanakan oleh seluruh muslim yang telah memenuhi kriteria (muzakki) untuk membersihkan hartanya dengan cara menyalurkan zakatnya pada golongan yang berhak menerima zakat (mustahik). Fungsi utama zakat ini bukan hanya sekedar menolong perekonomian mustahik, tetapi juga menjadi alat penyeimbang dalam sektor ekonomi suatu negara. Tujuan utama dari pengelolaan zakat yaitu merubah total para mustahik menjadi muzakki. Hal ini menunjukkan bahwa zakat berpotensi untuk mengatasi kesenjangan ekonomi dan kemiskinan suatu negara (Divisi Publikasi dan Jaringan PUSKAS BAZNAS, 2016).

Di Indonesia sendiri kemiskinan dan pemberantasan kemiskinan pada dasarnya masih menjadi problem lama yang perlu dibenahi, baik dilihat dari sudut ekonomi, sosial, maupun dari berbagai kategori kemiskinan lainnya yang dilihat dari berbagai ukuran dan sudut pandang (Divisi Riset dan Kajian PUSKAS BAZNAS, 2017). Menurut data yang dilansir oleh BPS (www.bps.go.id), jumlah penduduk dengan pendapatan perkapita per bulan di bawah garis kemiskinan per September 2018 masih sangat tinggi, yaitu mencapai 25.67 juta orang, atau 9,66\% dari total penduduk Indonesia.

Potensi dana zakat di Indonesia sangat besar. Telah banyak penelitian yang menginformasikan tentang potensi zakat tersebut. Dua diantaranya yaitu penelitian yang dilakukan oleh Firdaus, Beik, Irawan, dan Juanda tahun 2012 yang mengungkapkan bahwa terdapat potensi zakat sebesar Rp. 217 Triliun, serta Penelitian BAZNAS tahun 2015 yang menyatakan bahwa potensi zakat di Indonesia mencapai Rp. 286 Triliun. Data terbaru fundraising ZIS nasional oleh OPZ resmi, pada tahun 2017 fundraising ZIS baru mencapai sekitar Rp. 6 Triliun (Divisi Publikasi dan Jaringan PUSKAS BAZNAS, 2017). Dari data-data tersebut sangat jelas terlihat bahwa ada permasalahan yang serius yang menyebabkan kesenjangan antara potensi dengan realitas menjadi begitu jauh.

Permasalahan tersebut bisa jadi dipengaruhi oleh beberapa faktor. Pertama, rendahnya kesadaran muzakki; Kedua, kurangnya dukungan pemerintah untuk mengimplementasikan UU Zakat No. 23/2011; Ketiga, basis zakat masih terfokus pada dua item objek zakat yaitu zakat fitrah dan Profesi/Kasb; Keempat, masih rendahnya insentif bagi muzakki terkait dengan zakat sebagai pengurang pajak; Kelima, masyarakat menilai bahwa organisasi pengelola zakat resmi masih kurang profesional sehingga menyebabkan kepercayaan masyarakat rendah; Keenam, distribusi dana zakat masih terfokus ke dalam komsumtif mustahik (Divisi Publikasi dan Jaringan PUSKAS BAZNAS, 2017).

\section{Zakat Core Principles}

Untuk mengatasi masalah-masalah tersebut, sejak tahun 2016 telah diperkenalkan sebuah standar pengelolaan zakat yang bernama Zakat Core Principles (ZCP) dalam forum "World Humanitarian Summit of United Nations" atau Forum Kemanusiaan PBB yang diselenggarakan di Istanbul, Turki. ZCP bertujuan untuk meningkatkan kualitas pengelolaan manajemen zakat agar semakin efektif dalam memobilisasi dana sosial publik bagi peningkatan kesejahteraan umat di berbagai belahan dunia. Untuk mendukung penerapannya di berbagai negara, prinsip-prinsip utama pengelolaan zakat 
disusun dengan memperhatikan kondisi spesifik di masing-masing negara, mendorong pengelolaan yang lebih governance, akomodatif dan sejalan dengan kerangka peraturan yang terkait dengan sub-sektor keuangan syariah lainnya, serta mendukung konektivitas dengan sektor riil dan pembangunan modal manusia (www.bi.go.id).

Zakat Core Principles (ZCP) merupakan sebuah dokumen yang berisi 18 prinsip yang mengatur 6 (enam) aspek atau dimensi utama pengelolaan zakat. Menurut Beik (2016) Keenam dimensi tersebut adalah landasan hukum, supervisi zakat, tata kelola zakat, fungsi intermediasi, manajemen resiko dan kesesuaian syariah. Hal yang menarik adalah bahwa lahirnya ZCP merupakan inisiatif Indonesia yang dalam hal ini diwakili oleh Bank Indonesia yang bekerjasama dengan BAZNAS, dan IRTI-IDB (Islamic Research and Training Institute-Islamic Development Bank). Ketiga institusi tersebut kemudian ditambah dengan perwakilan dari beberapa negara lain seperti Arab Saudi, Malaysia, India, Pakistan, Afrika Selatan, dll, sehingga membentuk sebuah tim internasional yang disebut dengan International Working Group on Zakat Principles (IWG-ZCP).

Ide pembuatan ZCP sendiri terinspirasi dari Basel Core Principles (BCP) atau yang secara resmi bernama Core Principles for Effective Banking Supervision, yaitu sebuah standar umum pengelolaan pada bidang perbankan yang berisi 29 prinsip yang telah diakui secara internasional. BCP bahkan sudah diterapkan di lebih dari 150 negara di dunia (Beik, Hanum, Muljawan, Yumanita, Fiona, dan Nazar, 2016). Hal inilah yang menyebabkan tim IWG-ZCP mengadopsi prinsip dalam BCP menjadi prinsip dalam ZCP. Setelah melewati proses yang panjang, akhirnya dokumen final ZCP selesai dan diperkenalkan dalam event PBB di Istanbul, Turki, seperti yang telah disebutkan di atas. Adapun 18 prinsip ZCP dapat dilihat pada tabel berikut ini (DEKS-BI, 2016).

Tabel 1. Struktur Zakat Core Principles

\begin{tabular}{|c|c|c|c|}
\hline No. & Kode & Aspek yang Diatur & Kata Kunci \\
\hline 1. & ZCP 1 & $\begin{array}{l}\text { Top of form, tujuan, } \\
\text { independensi, otoritas } \\
\text { Bottom of form. }\end{array}$ & $\begin{array}{l}\text { Hukum, peraturan, atau kerangka hukum } \\
\text { lainnya untuk pengawasan zakat harus jelas } \\
\text { didefinisikan guna memberikan kewenangan } \\
\text { masing-masing dan bertanggung jawab den- } \\
\text { gan kekuatan hukum yang diperlukan dan in- } \\
\text { dependensi. }\end{array}$ \\
\hline 2. & $\mathrm{ZCP} 2$ & $\begin{array}{l}\text { Kegiatan Amil yang } \\
\text { diizinkan }\end{array}$ & $\begin{array}{l}\text { Hukum, regulasi atau aturan lain harus secara } \\
\text { jelas mendefinisikan kegiatan-kegiatan yang } \\
\text { diizinkan dilakukan oleh organisasi pengelola } \\
\text { zakat sesuai prinsip syariah, termasuk dalam } \\
\text { hal penghimpunan zakat, pengelolaan keuan- } \\
\text { gan, pendistribusian zakat dan aktivitas lain- } \\
\text { nya. }\end{array}$ \\
\hline 3. & ZCP 3 & Kriteria Perijinan & $\begin{array}{l}\text { Otoritas perijinan harus memiliki kewenan- } \\
\text { gan regulasi untuk menentukan kriteria per- } \\
\text { izinan organisasi pengelola zakat dan meno- } \\
\text { lak aplikasi yang tidak memenuhi kriteria. }\end{array}$ \\
\hline
\end{tabular}




\begin{tabular}{|c|c|c|c|}
\hline No. & Kode & Aspek yang Diatur & Kata Kunci \\
\hline 4. & ZCP 4 & $\begin{array}{l}\text { Pendekatan Penga- } \\
\text { wasan }\end{array}$ & $\begin{array}{l}\text { Pengawas zakat memiliki skema pengawasan } \\
\text { yang terintegrasi yang mencakup semua aspek } \\
\text { dari pengumpulan zakat dan penyaluran zakat }\end{array}$ \\
\hline 5. & ZCP 5 & $\begin{array}{l}\text { Teknik dan Instrumen } \\
\text { Pengawasan }\end{array}$ & $\begin{array}{l}\text { Pengawas zakat menggunakan teknik dan } \\
\text { instrumen pengawasan yang memadai un- } \\
\text { tuk menerapkan melakukan pengawasan dan } \\
\text { mempekerjakan sumber daya pengawasan } \\
\text { yang telah divalidasi dan diverifikasi }\end{array}$ \\
\hline 6. & ZCP 6 & Pelaporan Pengawasan & $\begin{array}{l}\text { Supervisor zakat mengumpulkan informasi, } \\
\text { mereview dan menganalisis kinerja organisasi } \\
\text { pengelola zakat. }\end{array}$ \\
\hline 7. & ZCP 7 & $\begin{array}{l}\text { Kekuatan Pengawas } \\
\text { dalam Koreksi dan }\end{array}$ & $\begin{array}{l}\text { Supervisor zakat memiliki berbagai instrumen } \\
\text { pengawasan yang memadai untuk melakukan }\end{array}$ \\
\hline & & Sanksi & $\begin{array}{l}\text { puan untuk mencabut izin organisasi pengelo- } \\
\text { la zakat dan merekomendasikan izin pencab- } \\
\text { utan }\end{array}$ \\
\hline 8. & ZCP 8 & $\begin{array}{l}\text { Tata Kelola Amil } \\
\text { (Good Amil Gover- } \\
\text { nance) }\end{array}$ & $\begin{array}{l}\text { Pengawas zakat menentukan bahwa organi- } \\
\text { sasi pengelola zakat memiliki kebijakan dan } \\
\text { proses amil governance yang kuat, yang me- } \\
\text { liputi kepatuhan syariah, instrument strategis, } \\
\text { lingkungan pengendalian, pengetahuan mana- } \\
\text { jemen zakat, dan tanggungjawab dewan lem- } \\
\text { baga zakat. }\end{array}$ \\
\hline 9. & ZCP 9 & $\begin{array}{l}\text { Manajemen Penghim- } \\
\text { punan }\end{array}$ & $\begin{array}{l}\text { Pengawas zakat menentukan bahwa organi- } \\
\text { sasi pengelola zakat memiliki kebijakan dan } \\
\text { proses yang memadai untuk penilaian nishab } \\
\text { dan aset yang dizakati }\end{array}$ \\
\hline 10. & ZCP 10 & $\begin{array}{l}\text { Manajemen Pember- } \\
\text { dayaan }\end{array}$ & $\begin{array}{l}\text { Supervisor zakat menentukan bahwa organi- } \\
\text { sasi pengelola zakat memiliki kebijakan dan } \\
\text { proses yang memadai untuk mengelola dana } \\
\text { zakat dan sistem distribusinya. }\end{array}$ \\
\hline 11. & ZCP 11 & $\begin{array}{l}\text { Risiko Negara dan } \\
\text { Transfer }\end{array}$ & $\begin{array}{l}\text { Pengawas zakat menentukan bahwa organi- } \\
\text { sasi pengelola zakat memiliki kebijakan dan } \\
\text { proses yang memadai untuk mengendalikan } \\
\text { risiko negara dan risiko transfer zakat dalam } \\
\text { kegiatan transfer zakat internasional mereka }\end{array}$ \\
\hline 12. & ZCP 12 & $\begin{array}{l}\text { Risiko Reputasi dan } \\
\text { Kerugian Muzakki }\end{array}$ & $\begin{array}{l}\text { Pengawas zakat menentukan bahwa organi- } \\
\text { sasi pengelola zakat memiliki kerangka kerja } \\
\text { manajemen yang memadai untuk menangani } \\
\text { risiko sistem, reputasi, dan risiko kerugian } \\
\text { muzakki }\end{array}$ \\
\hline
\end{tabular}


L. Hamdani dkk, Solusi Permasalahan Perzakatan di BAZNAS dengan Metode ANP...

\begin{tabular}{|c|c|c|c|}
\hline No. & Kode & Aspek yang Diatur & Kata Kunci \\
\hline 13. & ZCP 13 & Risiko Pendistribusian & $\begin{array}{l}\text { Lembaga zakat harus dapat mengurangi risiko } \\
\text { pendistribusian seperti posisi keuangan yang } \\
\text { sehat dan misalokasi kegiatan pendayagunaan }\end{array}$ \\
\hline \multirow[t]{2}{*}{14.} & ZCP 14 & $\begin{array}{l}\text { Risiko Operasional } \\
\text { dan Kepatuhan Sya- } \\
\text { riah }\end{array}$ & $\begin{array}{l}\text { Pengawas zakat menentukan bahwa organisa- } \\
\text { si pengelola zakat harus memiliki manajemen } \\
\text { risiko operasional yang tepat untuk }\end{array}$ \\
\hline & & & $\begin{array}{l}\text { meminimalkan potensi praktik penipuan, anti- } \\
\text { sipasi terhadap kerusakan sistem dan potensi } \\
\text { gangguan lainnya. }\end{array}$ \\
\hline 15. & ZCP 15 & $\begin{array}{l}\text { Pengawasan Syariah } \\
\text { dan Audit Internal }\end{array}$ & $\begin{array}{l}\text { Pengawas zakat menentukan organisasi pen- } \\
\text { gelola zakat untuk memiliki pengawasan sya- } \\
\text { riah dan kerangka kerja audit internal yang } \\
\text { sesuai untuk membangun dan memelihara } \\
\text { lingkungan operasi yang terkontrol dengan } \\
\text { baik sesuai hukum syariah }\end{array}$ \\
\hline 16. & ZCP 16 & $\begin{array}{l}\text { Laporan Keuangan } \\
\text { dan Audit Eksternal }\end{array}$ & $\begin{array}{l}\text { Pengawas zakat menentukan bahwa organi- } \\
\text { sasi pengelola zakat memiliki catatan laporan } \\
\text { keuangan, publikasi tahunan dan fungsi audit } \\
\text { eksternal yang terpercaya }\end{array}$ \\
\hline 17. & ZCP 17 & $\begin{array}{l}\text { Pengungkapan dan } \\
\text { Transparansi }\end{array}$ & $\begin{array}{l}\text { Supervisor zakat menentukan bahwa organi- } \\
\text { sasi pengelola zakat secara teratur mempub- } \\
\text { likasikan informasi konsolidasi yang mudah } \\
\text { diakses dan cukup mencerminkan kondisi } \\
\text { keuangan dan kinerja. }\end{array}$ \\
\hline 18. & ZCP 18 & $\begin{array}{l}\text { Penyalahgunaan } \\
\text { Layanan Zakat }\end{array}$ & $\begin{array}{l}\text { Pengawas zakat menentukan bahwa organi- } \\
\text { sasi pengelola zakat memiliki kebijakan dan } \\
\text { proses yang tepat untuk mereview, mempro- } \\
\text { mosikan etika Islam dan standar profesional } \\
\text { serta untuk mencegah kegiatan kriminal. }\end{array}$ \\
\hline
\end{tabular}

Penelitian yang khusus membahas tentang implementasi ZCP dengan menggunakan metode Analytical Network Process (ANP) belum pernah dilakukan sebelumnya. Penelitian yang telah ada hanya membahas masalah tentang zakat dari sudut pandang umum. Seperti yang dilakukan oleh Siregar (2016), dimana penelitiannya membahas tentang problematika fundraising zakat di Sumatera Utara. Hasil penelitiannya antara lain bahwa Sumatera Utara memiliki potensi penghimpunan zakat yang besar tapi kinerja belum optimal, undang-undang dan peraturan zakat yang belum terlaksana secara maksimal, perhatian pemerintah belum maksimal terhadap pengelolaan zakat di provinsi tersebut dan SDM yang belum profesional.

Penelitian berikutnya dilakukan oleh Rusydiana dan Firmansyah (2017). Penelitian ini membahas tentang kriteria prioritas prinsip inti zakat menggunakan model AHP (Analytical Hierarchy Process). Menurut kedua peneliti, model AHP diperlukan untuk memperbaiki sistem zakat dan mengindentifikasi kelemahan seperti pengawasan dan 
regulasi. Ada 5 prinsip dasar dalam AHP yaitu Peraturan, Pengawasan, Pengumpulan, Pengelolaan, Manajemen Risiko serta audit dan transparansi. Kesimpulan dari penelitian tersebut yaitu masyarakat saat ini menilai bahwa pengelolaan BAZNAS masih belum maksimal bila dibandingkan dengan LAZNAS. Ada beberapa hal yang selalu dikritisi oleh masyarakat antara lain; aturan, yang dirasa hanya dilakukan di BAZNAS pusat saja dan tidak dilakukan di BAZNAS tingkat daerah; pengumpulan, yang masih belum maksimal; pengawasan, yang lemah yang disebabkan banyak pensiunan PNS atau pejabat daerah yang menjadi komisioner di BAZNAS. Oleh karena itu diperlukan manajemen risiko yang kuat dan dinamis, agar pengelolaan zakat semakin maju dan baik.

Amalia (2017) dalam penelitiannya mengusulkan beberapa rekomendasi yaitu: 1). Pemerintah harus mengembangkan standar tata kelola syariah untuk lembaga zakat di Indonesia; 2). Perlunya mendesain pedoman standarisasi sistem pelaporan keuangan, sistem pengawasan syariah, dan audit keuangan sistem syariah; 3). Perlu mempertahankan kompetensi sumber daya manusia dalam pengelolaan zakat (sertifikasi amil); serta, 4). Pemerintah diharapkan untuk mempertahankan perannya dalam mengembangkan, mengendalikan, dan mengawasi manajemen zakat di Indonesia.

Penelitian berikutnya yang dilakukan oleh Huda, Anggraini, Ali, Mardoni, dan Rini (2014) dimana penelitian ini memetakan prioritas masalah dan solusi dalam pengelolaan zakat menggunakan metode AHP, yaitu: regulator, OPZ, serta muzakki dan mustahik. Hasil penelitian adalah bahwa Model AHP di Banten dan Kalimantan Selatan menghasilkan skor prioritas sama, yaitu bahwa lembaga yang paling diandalkan dalam pemecahan masalah pengelola zakat adalah OPZ dan prioritas solusi regulator adalah sertifikasi amil. Penelitian terakhir sebagai pembanding adalah penelitian yang dilakukan oleh Firmansyah dan Sukmana (2014) yang memiliki kesimpulan bahwa penyebab terjadinya problematika zakat di BAZNAS kota Tasikmalaya ada 2 yaitu masalah internal dan eksternal. Solusinya untuk masalah internal berupa maksimalisasi kerja pimpinan serta transparansi distribusi, sedangkan masalah eksternal yaitu sosialisasi BAZNAS dan dukungan ulama.

Penelitian ini sendiri bermula dari keingintahuan peneliti tentang mengapa ZCP yang telah di-launching oleh BAZNAS pusat justru hingga saat ini belum dipraktikkan secara maksimal di BAZNAS tingkat daerah sehingga masih terjadi kesenjangan antara potensi pengumpulan zakat dengan realisasinya. Padahal, jika ZCP tersebut bisa diimplementasikan maka akan berperan penting bagi terciptanya Sustainable Development Goals (SDG).

\section{METODOLOGI PENELITIAN}

Metodologi yang dipakai di penelitian ini yaitu metode Analytic Network Process (ANP). Menurut Saaty (dalam Hermawan, Saptono, dan Anggrainingsih, 2016), ANP merupakan perkembangan dari metode Analytic Hierarchy Process (AHP) yang merupakan salah satu teori pengukuran melalui perbandingan berpasangan. Kusnadi, Surarso, dan Syafei (2016) menyatakan bahwa metode ANP digunakan dalam bentuk penyelesaian dengan pertimbangan atas penyesuaian kompleksitas masalah disertai adanya skala prioritas yang menghasilkan pengaruh prioritas terbesar. Menurut Tanjung dan Devi (2013), ANP memiliki fungsi yang penting karena dapat membantu melakukan 
pengukuran dan sintesis terhadap sejumlah faktor dalam hirarki atau jaringan untuk menyelesaikan peroblematika tertentu.

Menurut Ascarya (2005), ANP memiliki tiga fungsi, yaitu: menstruktur kompleksitas, pengukuran, dan sintesis. Lebih lanjut Ascarya berpendapat bahwa problematika yang beranekaragam dan kompleks tidak akan dapat diurai dan diselesaikan bila tidak distruktur dengan baik. ANP menggunakan pengukuran dalam skala rasio pada semua level dari hierarki/jaringan, termasuk level terendah (alternatif dalam model pilihan). Pengukuran dalam skala rasio diperlukan untuk menggambarkan proporsi atau prioritas setiap elemen. Skala rasio ini menjadi semakin penting jika prioritas tidak hanya diperuntukan untuk aplikasi pilihan, namun untuk aplikasi lainnya, seperti aplikasi untuk alokasi sumber daya.

ANP memiliki tiga prinsip dasar, yaitu; dekomposisi, yang dipergunakan untuk membuat struktur problematika yang kompleks, comparative judgements atau penilaian komparasi, yang dilakukan untuk membangun pairwise comparison atau pembanding pasangan dari semua kombinasi elemen-elemen dalam cluster dilihat dari cluster induknya, dan komposisi hirarki atau sintesis dari prioritas,yang diterapkan untuk mengalikan prioritas lokal dari elemen-elemen dalam cluster dengan prioritas global dari elemen induk (Ascarya, 2005).

Penelitian ini menggunakan tujuh orang responden yang pemilihannya dilakukan secara purposive sampling. Responden tersebut dipilih dengan kriteria memiliki keahlian dan pemahaman tentang implementasi ZCP. Dalam ANP, jumlah responden tidak digunakan sebagai syarat patokan validitas. Syarat responden yang sah dalam ANP adalah bahwa mereka seorang pakar atau expert di bidangnya. Maka dari itu, responden yang dipilih dalam penelitian ini terdiri dari para pakar, peneliti, dan praktisi yang berkecimpung dalam bidang zakat. Data dikumpulkan dengan menggunakan sumber primer yaitu kuesioner dan wawancara serta sumber sekunder yaitu berasal dari literatur jurnal dan buku.

Pertanyaan dalam kuesioner ANP yaitu perbandingan pasangan (pairwise comparison) antara elemen dan cluster untuk mengetahui mana di antara keduanya yang lebih besar effect-nya (lebih dominan) dan seberapa besar perbedaannya. Ketika mengisi kuesioner, para responden harus didampingi oleh peneliti dengan tujuan untuk menjaga konsistensi atau keakuratan dari jawaban yang diberikan. Adapun perbandingan skala nilai tercantum pada tabel dibawah ini.

Tabel 2. Perbandingan Skala Verbal dan Skala Numerik

\begin{tabular}{cl}
\hline Skala Numerik & \multicolumn{1}{c}{ Skala Verbal } \\
\hline 9 & Amat sangat besar pengaruhnya \\
8 & Sangat lebih besar pengaruhnya \\
7 & Lebih besar pengaruhnya \\
5 & Sedikit lebih besar pengaruhnya \\
4 & \\
3 & \\
\hline
\end{tabular}




\begin{tabular}{cc}
\hline Skala Numerik & \multicolumn{1}{c}{ Skala Verbal } \\
\hline 2 & Sama besar pengaruhnya \\
\hline
\end{tabular}

(Sumber: Saaty, 2016)

\section{HASIL DAN PEMBAHASAN}

Untuk menemukan solusi dari masalah zakat di BAZNAS dengan menggunakan metode ANP dan implementasi ZCP, penulis melakukan in depth interview kepada responden dan melakukan library research melalui penelusuran literatur-literatur yang terkait dengan kajian penelitian sebagai starting point. Selanjutnya, penulis membuat dekomposisi masalah yang dikonstruksikan dalam sebuah model agar dapat memberikan kemudahan bagi peneliti ataupun responden dalam memahami solusi tentang masalah zakat tersebut. Dekomposisi masalah menghasilkan 6 (enam) bentuk cluster kerangka model analisis masalah yang dapat dilihat pada kerangka model seperti pada Gambar 1.

Cara menganalisis kerangka model tersebut yaitu item Aspek mempunyai tiga elemen yaitu; problem BAZNAS, problem masyarakat dan problem Pemerintah. Item Masalah pada sisi BAZNAS memiliki tiga elemen, yaitu; BAZNAS belum menjalankan esensi dari ZCP, manajemen pengelolaan dan sumber daya manusia yang belum maksimal, serta belum mandiri secara formal dan finansial. Masalah pada sisi masyarakat memiliki tiga elemen, yaitu belum mendapatkan sosialisasi dan edukasi tentang ZCP, menuntut adanya akuntabilitas dan transparansi terhadap BAZNAS, serta harus ada syariah kontrol terhadap BAZNAS. Terakhir, masalah dari sisi pemerintah memiliki tiga elemen, yaitu; kurangnya kebijakan pendukung, kurangnya dana insentif dan kurangnya sinergi antar organisasi pengelola zakat.

Item solusi memiliki empat elemen, yaitu; peningkatan pemahaman esensi dan implementasi tentang ZCP, perbaikan manajemen pengelolaan SDM dan BAZNAS mandiri secara formal dan finansial, Sosialisasi dan edukasi ZCP, BAZNAS harus lebih akuntabel, transparan, serta harus dilakukan syariah kontrol terhadap BAZNAS, serta revisi regulasi/insentif/tegas/sinergitas antar OPZ dengan Pemerintah. Item yang terakhir, strategi, memiliki tiga elemen, yaitu; substansi ZCP yang perlu diimplementasikan dan BAZNAS harus mandiri secara formal dan finansial, sosialisasi dan edukasi yang terus menerus dan harus ada syariah kontrol terhadap BAZNAS, pemerintah harus mendukung ZCP dalam berbagai aspek dan harus ada sinergitas organisasi pengelolan zakat.

Berikutnya, dari hasil wawancara yang dilakukan oleh peneliti kepada 7 orang responden yang telah terpilih, kemudian dibuatlah sebuah kerangka model. Setelah itu kerangka model tersebut dikonsultasikan dan diverifikasikan kembali kepada salah satu responden. Akhirnya, dari kerangka model itulah lahir kuesioner ANP yang disebar kembali kepada 7 responden yang terpilih. Setelah itu, nilai asli responden dihitung dan diinput menggunakan aplikasi Super Decision dengan metode ANP. Hasil dari nilai asli sintesis per responden yang sudah diolah melalui aplikasi Super Decision dapat dilihat pada Tabel 3.

Para responden memiliki opini yang berbeda tentang prioritas mana yang lebih penting di antara 3 (tiga) prioritas, yaitu prioritas masalah, prioritas solusi, atau prioritas 




Gambar 1. Kerangka Model

Tabel 3. Hasil Sintesis Nilai Responden tentang Solusi Permasalahan Perzakatan di BAZNAS

\begin{tabular}{|c|c|c|c|c|c|c|c|c|}
\hline No & Masalah & R1 & R2 & $\mathrm{R} 3$ & R4 & R5 & R6 & R7 \\
\hline 1 & BAZNAS & 0,29696 & 0,53961 & 0,66667 & 0,42857 & 0,20001 & 0,33333 & 0,33333 \\
\hline 2 & Masyarakat & 0,16343 & 0,16343 & 0,16666 & 0,14285 & 0,40000 & 0,33333 & 0,33333 \\
\hline 3 & Pemerintah & 0,53962 & 0,29696 & 0,16666 & 0,42857 & 0,40000 & 0,33333 & 0,33333 \\
\hline \multicolumn{9}{|c|}{ Masalah BAZNAS } \\
\hline 1 & $\begin{array}{l}\text { Belum Menjalankan } \\
\text { Esensi ZCP Secara Mak- } \\
\text { simal }\end{array}$ & 0,27021 & 0,18750 & 0,47867 & 0,50000 & 0,30000 & 0,27021 & 0,3 \\
\hline 2 & $\begin{array}{l}\text { Manajemen Pengelolaan } \\
\text { dan SDM yang Belum } \\
\text { Maksimal }\end{array}$ & 0,17123 & 0,60938 & 0,11376 & 0,25000 & 0,35000 & 0,17122 & 0,35 \\
\hline 3 & $\begin{array}{l}\text { Belum Mandiri secara } \\
\text { Formal dan Finansial }\end{array}$ & 0,55856 & 0,20313 & 0,40757 & 0,25000 & 0,35000 & 0,55856 & 0,35 \\
\hline
\end{tabular}


Jurnal Muqtasid, 10(1) 2019: 40-56

49

\begin{tabular}{|c|c|c|c|c|c|c|c|c|}
\hline No & Masalah & $\mathrm{R} 1$ & $\mathrm{R} 2$ & $\mathrm{R} 3$ & $\mathrm{R} 4$ & $\mathrm{R} 5$ & R6 & R7 \\
\hline \multicolumn{9}{|c|}{ Masalah Masyarakat } \\
\hline 1 & $\begin{array}{l}\text { Belum Mendapatkan } \\
\text { Sosialisasi dan edukasi } \\
\text { Tentang ZCP }\end{array}$ & 0,25829 & 0,42857 & 0,56954 & 0,25829 & 0,33333 & 0,40000 & 0,2 \\
\hline 2 & $\begin{array}{l}\text { Menuntut Akuntabilitas } \\
\text { dan Transparansi dari } \\
\text { BAZNAS }\end{array}$ & 0,63699 & 0,14285 & 0,33307 & 0,63698 & 0,33333 & 0,40000 & 0,2 \\
\hline 3 & $\begin{array}{l}\text { Menuntut Diadakannya } \\
\text { Syariah Kontrol terhadap } \\
\text { BAZNAS }\end{array}$ & 0,10473 & 0,42857 & 0,09739 & 0,10473 & 0,33333 & 0,20000 & 0,6 \\
\hline \multicolumn{9}{|c|}{ Masalah Pemerintah } \\
\hline 1 & $\begin{array}{l}\text { Kurangnya Kebijakan } \\
\text { Pendukung }\end{array}$ & 0,27247 & 0,22704 & 0,35091 & 0,12500 & 0,38493 & 0,33333 & 0,3 \\
\hline 2 & Kurangnya Dana insentif & 0,09480 & 0,22704 & 0,18906 & 0,37500 & 0,38493 & 0,33333 & 0,3 \\
\hline 3 & $\begin{array}{l}\text { Kurangnya sinergi Antar } \\
\text { OPZ }\end{array}$ & 0,16533 & 0,42359 & 0,10911 & 0,12500 & 0,08735 & 0,16667 & 0,3 \\
\hline \multicolumn{9}{|c|}{ Solusi } \\
\hline 1 & $\begin{array}{l}\text { BAZNAS Harus Mening- } \\
\text { katkan Pemahaman Akan } \\
\text { Esensi dan Implementasi } \\
\text { tentang ZCP }\end{array}$ & 0,46740 & 0,12232 & 0,35091 & 0,37500 & 0,14279 & 0,16667 & 0,1 \\
\hline 2 & $\begin{array}{l}\text { BAZNAS Harus Melaku- } \\
\text { kan Perbaikan Manaje- } \\
\text { men Pengelolaan dan } \\
\text { SDM, serta BAZNAS } \\
\text { Harus Mandiri Secara } \\
\text { Formal dan Finansial }\end{array}$ & 0,16343 & 0,20000 & 0,33307 & 0,45454 & 0,42857 & 0,40000 & 0,2 \\
\hline 3 & $\begin{array}{l}\text { BAZNAS Harus Melaku- } \\
\text { kan Sosialisasi dan } \\
\text { Edukasi Tentang ZCP } \\
\text { Kepada Masyarakat, } \\
\text { BAZNAS Harus Lebih } \\
\text { Akuntabel dan Transpar- } \\
\text { an, serta Harus Dilaku- } \\
\text { kan Syariah kontrol } \\
\text { Terhadap BAZNAS }\end{array}$ & 0,53961 & 0,20000 & 0,56954 & 0,45454 & 0,14285 & 0,20000 & 0,2 \\
\hline 4 & $\begin{array}{l}\text { Revisi Regulasi/Pen- } \\
\text { dukung/Insentif/Tegas/ } \\
\text { dan Sinergi Antara OPZ } \\
\text { dengan Pemerintah }\end{array}$ & 0,29696 & 0,60000 & 0,09739 & 0,09091 & 0,42857 & 0,40000 & 0,2 \\
\hline
\end{tabular}


L. Hamdani dkk, Solusi Permasalahan Perzakatan di BAZNAS dengan Metode ANP...

\begin{tabular}{|c|c|c|c|c|c|c|c|c|}
\hline No & Masalah & $\mathrm{R} 1$ & $\mathrm{R} 2$ & $\mathrm{R} 3$ & $\mathrm{R} 4$ & R5 & R6 & R7 \\
\hline \multicolumn{9}{|c|}{ Strategi } \\
\hline 1 & $\begin{array}{l}\text { Menentukan Substansi } \\
\text { ZCP yang Perlu Diim- } \\
\text { plementasikan dan } \\
\text { BAZNAS Harus Mandiri } \\
\text { Secara Formal dan Finan- } \\
\text { sial }\end{array}$ & 0,29696 & 0,50000 & 0,71428 & 0,42857 & 0,33333 & 0,29696 & 0,2 \\
\hline 2 & $\begin{array}{l}\text { Sosialisasi dan Edukasi } \\
\text { yang Terus Menerus } \\
\text { Tentang ZCP Kepada } \\
\text { Masyarakat dan Harus } \\
\text { Ada Syariah Kontrol } \\
\text { Terhadap BAZNAS }\end{array}$ & 0,53961 & 0,25000 & 0,14286 & 0,42857 & 0,33333 & 0,16342 & 0,2 \\
\hline 3 & $\begin{array}{l}\text { Pemerintah Harus } \\
\text { Mendukung ZCP Dalam } \\
\text { Berbagai Aspek dan Ha- } \\
\text { rus Ada Sinergitas OPZ }\end{array}$ & 0,16342 & 0,25000 & 0,14286 & 0,14286 & 0,33333 & 0,53962 & 0,2 \\
\hline
\end{tabular}

strategi berkaitan dengan masalah zakat di BAZNAS. Untuk mengetahui prioritas mana yang mendapatkan nilai paling tinggi hingga yang paling rendah, dibuatlah urutan prioritas berdasarkan hasil kuesioner dari responden dengan cara mencari nilai rataratanya. Hasilnya seperti yang digambarkan dalam tabel hasil geometric mean di bawah ini.

Tabel 4. Hasil Geometric Mean terkait Permasalahan Perzakatan dan Solusinya

\begin{tabular}{|c|c|c|}
\hline & Aspek & Geometric Mean \\
\hline 1 & BAZNAS & $0,7,867785$ \\
\hline 2 & Masyarakat & $0,6,859289$ \\
\hline 3 & Pemerintah & $0,7,534025$ \\
\hline \multicolumn{3}{|c|}{ Masalah BAZNAS } \\
\hline 1 & Belum Menjalankan Esensi ZCP Secara Maksimal & $0,7,284706$ \\
\hline 2 & Manajemen Pengelolaan dan SDM yang Belum Maksimal & $0,7,147061$ \\
\hline 3 & Belum Mandiri Secara Formal dan Finansial & $0,6,651864$ \\
\hline \multicolumn{3}{|c|}{ Masalah Masyarakat } \\
\hline 1 & Belum Mendapatkan Sosialisasi dan Edukasi Tentang ZCP & $0,6,744839$ \\
\hline 2 & Menuntut Akuntabilitas dan Transparansi dari BAZNAS & $0,6,605661$ \\
\hline 3 & Menuntut Adanya Syariah Kontrol terhadap BAZNAS & $0,5,273362$ \\
\hline \multicolumn{3}{|c|}{ Masalah Pemerintah } \\
\hline 1 & Kurangnya Kebijakan Pendukung & $0,7,946187$ \\
\hline 2 & Kurang Dana Insentif & $0,7,373869$ \\
\hline 3 & Kurangnya Sinergi antar OPZ & $0,6,226613$ \\
\hline \multicolumn{3}{|c|}{ Pemecahan } \\
\hline 1 & $\begin{array}{l}\text { BAZNAS Harus Meningkatkan Pemahaman tentang Esensi dan } \\
\text { Implementasi ZCP }\end{array}$ & $0,7,460133$ \\
\hline 2 & $\begin{array}{l}\text { BAZNAS Harus Memperbaiki Manajemen Pengelolaan dan SDM } \\
\text { serta BAZNAS Harus Mandiri Secara Formal dan Finansial }\end{array}$ & 7,643416 \\
\hline
\end{tabular}




\begin{tabular}{clc}
\hline \multicolumn{1}{c}{ Aspek } & Geometric Mean \\
\hline 3 & $\begin{array}{l}\text { Sosialisasi dan Edukasi ZCP Kepada Masyarakat, BAZNAS Harus } \\
\text { Lebih Akuntabel dan Transparan, serta Harus Dilakukan Syariah } \\
\text { Kontrol Terhadap BAZNAS } \\
4\end{array}$ & $\begin{array}{l}\text { Revisi Regulasi/Pendukung/Insentif/Tegas, dan Harus Ada Sinergi } \\
\text { Antara OPZ dengan Pemerintah }\end{array}$ \\
\hline \multicolumn{1}{c}{ Strategi } & $0,7,79062$ \\
\hline 1 & $\begin{array}{l}\text { Substansi ZCP yang Perlu Diimplementasikan dan BAZNAS Harus } \\
\text { Mandiri Secara Formal dan Finansial }\end{array}$ & $0,7,867785$ \\
2 & $\begin{array}{l}\text { Sosialisasi dan Edukasi yang Terus Menerus dan Harus Ada Syariah } \\
\text { Kontrol Terhadap BAZNAS } \\
\text { Pemerintah Harus Mendukung ZCP Dalam Berbagai Aspek dan }\end{array}$ & $0,6,83174$ \\
\hline
\end{tabular}

Rater agreement adalah ukuran yang menunjukan tingkat kesesuaian (persetujuan) para responden (R1-Rn) terhadap suatu masalah dalam satu cluster. Adapun alat yang digunakan untuk mengukur rater agreement adalah Kendall's Coefficient of Concordance $(\mathrm{W}: 0<\mathrm{W} \leq 1) . \mathrm{W}=1$ menunjukan kesesuaian yang sempurna. Rater Agreement dalam penelitian ini adalah angka kesepakatan antara responden baik itu dari pakar zakat ataupun praktisi zakat dan akademisi. Tabel 4 merangkum hasil rater agreement seluruh cluster, tidak per node. Dalam interpretasinya bahwa skala nilai rater agreement ada 5 . W $=0$, berarti tidak ada angka kesepakatan, $\mathrm{W}=0.10$, berarti angka kesepakatannya lemah, $\mathrm{W}=0.30$, berarti angka kesepakatannya sedang, $\mathrm{W}=0.60$, berarti angka kesepakatannya kuat, dan $\mathrm{W}=1.00$, berarti angka kesepakatannya sempurna. Rater agreement tidak berkaitan dengan konsistensi index.

Tabel 4. Hasil Rater Agreement tentang Solusi Permasalahan Perzakatan di BAZNAS

\begin{tabular}{lll}
\hline No & Cluster & Rater Agreement \\
\hline 1 & Aspek & 0,137755 \\
2 & Baznas & 0,096939 \\
3 & Masyarakat & 0,021812 \\
5 & Pemerintah & 0,107143 \\
6 & Pemecahan & 0,343496 \\
7 & Strategi & 0,19898 \\
\hline
\end{tabular}

\section{Analisis Cluster}

Terkait pembahasan ini akan dijelaskan hasil sintesis pada berbagai cluster yang ada, yang diawali dari cluster aspek untuk menentukan solusi permasalahan zakat di BAZNAS. Berdasarkan hasil pengolahan data melalui Software Super Decision diperoleh prioritas masalah menurut opini seluruh responden sebagaimana terlihat pada diagram dibawah ini: 


\section{Aspek}

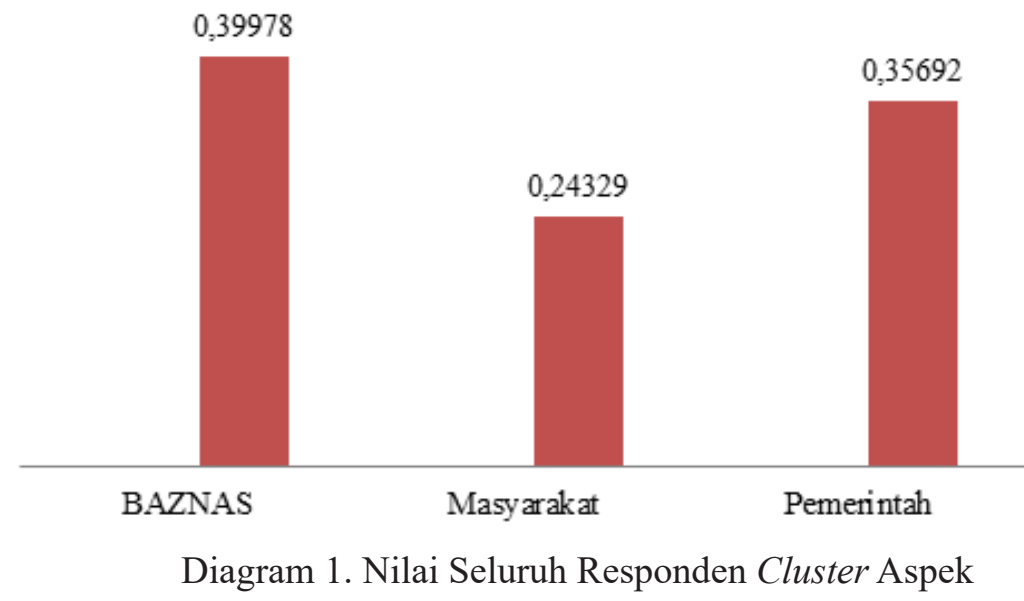

Diagram di atas menggambarkan bahwa berdasarkan opini gabungan para responden, problem yang paling prioritas adalah masalah yang terdapat di BAZNAS sebesar $39,9 \%$, setelah itu diikuti oleh pemerintah sebanyak 35,6\% dan yang menduduki urutan akhir yaitu masalah masyarakat sebanyak $24,3 \%$, Hasil perolehan nilai rater agreement seluruh responden yaitu $13,5 \%$, Hal ini menunjukan bahwa tingkat kesepakatan responden terhadap urutan prioritas masalah aspek antara lain BAZNAS, masyarakat, dan pemerintah sebesar $13,5 \%$.

\section{Masalah di BAZNAS}

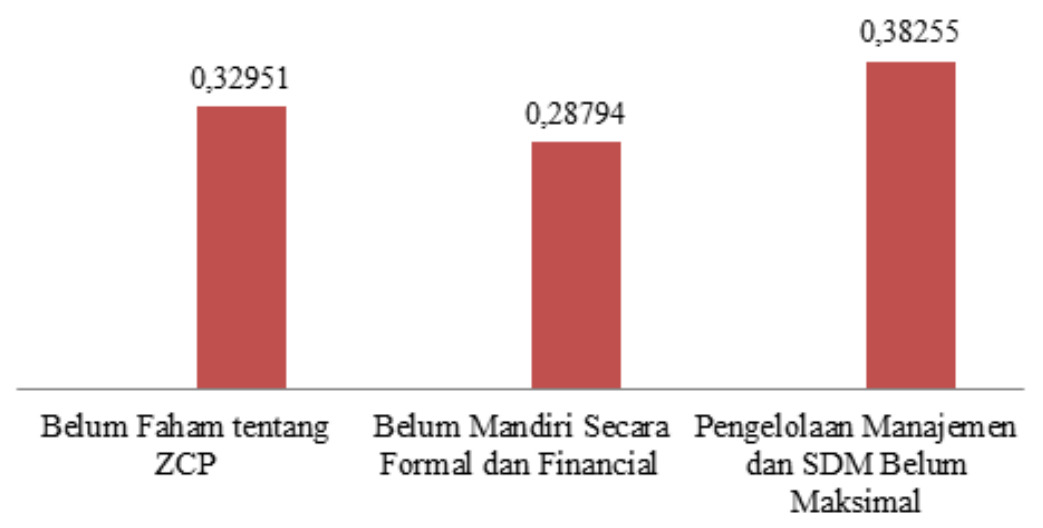

Diagram 2. Nilai Seluruh Responden Cluster Masalah di BAZNAS

Diagram 2 menggambarkan bahwa berdasarkan pendapat gabungan para responden, masalah BAZNAS yang paling prioritas adalah masalah kurangnya manajemen pengelolaan dan sumber daya manusia sebesar $38,2 \%$, selanjutnya diikuti oleh masalah belum paham tentang ZCP sebesar 32,9\% dan yang menempati urutan 
terakhir yaitu belum mandiri secara formal dan keuangan sebesar 28,7\%, Hasil perolehan nilai rater agreement seluruh responden adalah 9\%, Hal ini menunjukan bahwa tingkat kesepakatan responden terhadap urutan prioritas masalah BAZNAS adalah sebesar 9\%.

\section{Masalah di Masyarakat}

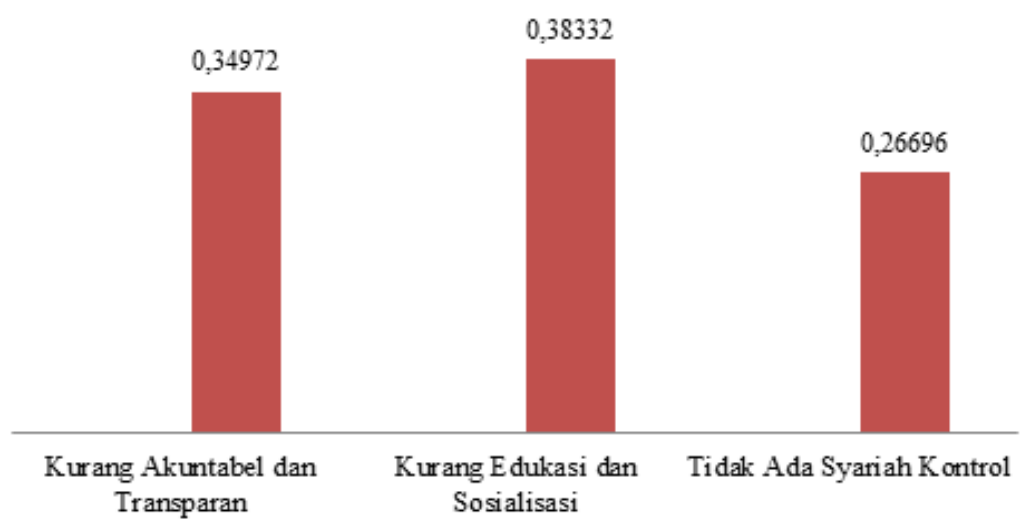

Diagram 3. Nilai Seluruh Responden Cluster Masalah di Masyarakat

Diagram 3 menggambarkan bahwa berdasarkan opini gabungan para responden, problem masyarakat yang paling prioritas adalah masalah kurangnya edukasi dan sosialisasi yang didapatkan sebesar 38\%, selanjutnya diikuti oleh masalah kurang akuntabel dan transparan dari BAZNAS yang dirasakan oleh masyarakat sebanyak $34 \%$ dan yang menduduki urutan akhir yaitu masalah merasa tidak ada kontrol syariah terhadap BAZNAS sebesar $26 \%$. Hasil perolehan nilai rater agreement seluruh responden sebanyak $2 \%$, Hal ini berarti bahwa tingkat kesepakatan responden terkait urutan prioritas problem kurang edukasi dan sosialisasi, kurang akuntabel dan transparan, serta tidak ada syariah kontrol adalah sebesar $2 \%$.

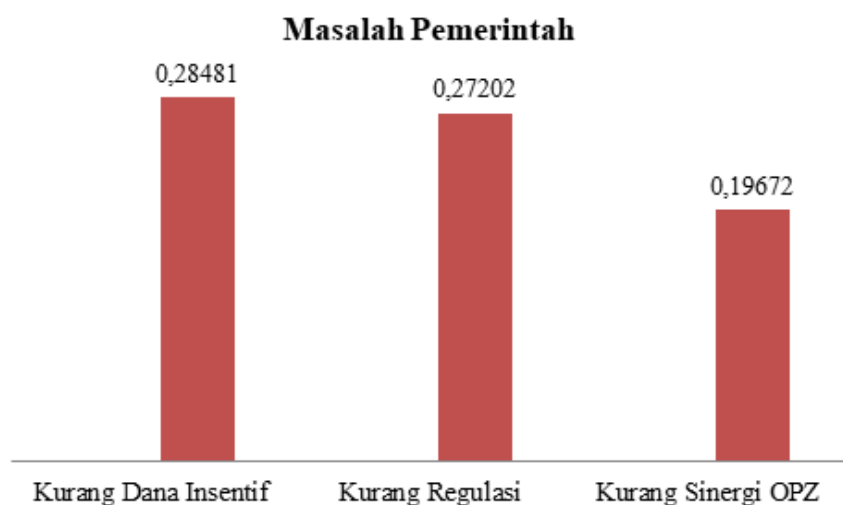

Diagram 4. Nilai Seluruh Responden Cluster Masalah Pemerintah

Diagram 4 menggambarkan bahwa berdasarkan opini gabungan para responden, 
problem pemerintah yang paling prioritas adalah kurang dana insentif sebesar $28 \%$, selanjutnya diikuti oleh masalah kurang regulasi sebesar $27 \%$, Setelah itu yang menduduki urutan ketiga dengan porsi yang kecil yaitu problem kurang sinergi organisasi pengelola zakat sebesar 19\%. Hasil perolehan nilai rater agreement seluruh responden yaitu $10 \%$. Hal ini menunjukan terkait tingkat kesepakatan responden terhadap urutan prioritas problem pemerintah yaitu kurang dana insentif dan kurang regulasi dan kurang sinergitas organisasi pengelola zakat adalah rendah, karena nilainya $10 \%$.

\section{Solusi}

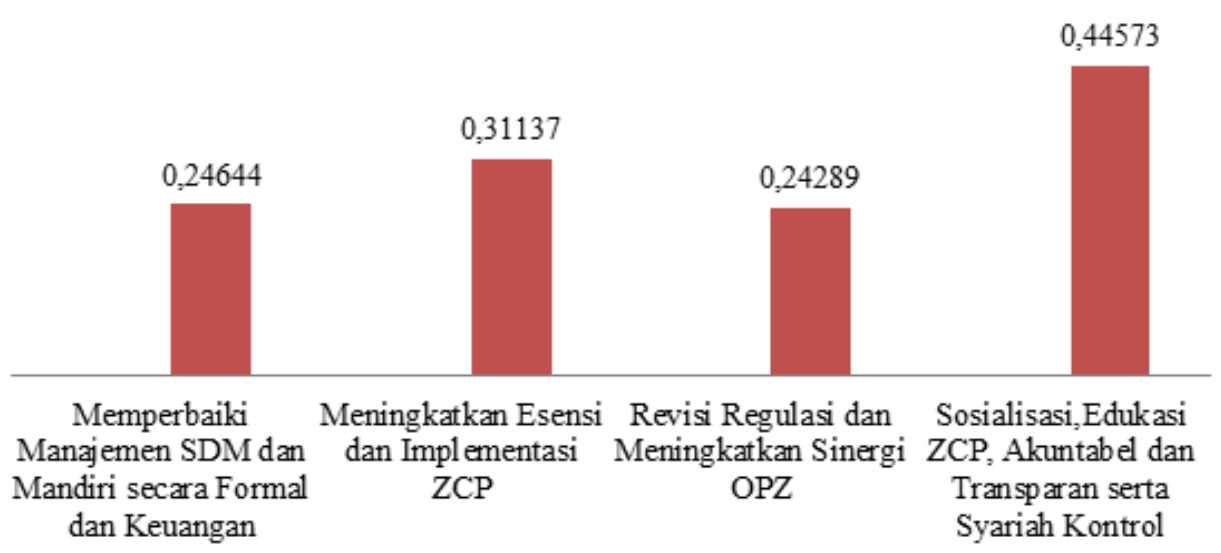

Diagram 5. Nilai Seluruh Responden Cluster Solusi

Berikutnya, diagram 5 menggambarkan bahwa merujuk pada opini gabungan para responden, solusi yang paling prioritas adalah solusi sosialisasi, edukasi ZCP dan akuntabel, transparan, syariah kontrol yaitu sebesar 44\%. Prioritas kedua ditempati oleh solusi meningkatkan esensi dan implementasi ZCP sebanyak 31\%. Urutan ketiga yaitu solusi memperbaiki manajemen sumber daya manusia dan mandiri secara lembaga dan

\section{Strategi BAZNAS}



Diagram 6. Nilai Seluruh Responden Cluster Strategi BAZNAS 
keuangan sebanyak 24,64\%, dan yang menempati urutan terakhir adalah solusi revisi regulasi dan meningkatkan sinergitas organisasi pengelola zakat sebanyak 24,28\%. Hasil perolehan nilai rater agreement seluruh responden yaitu 34\%. Ini berarti bahwa tingkat kesepakatan responden sedang terhadap urutan prioritas solusi sebesar 34\%.

Terakhir, diagram 6 menunjukkan opini gabungan para responden tentang strategi yang paling prioritas adalah implementasi ZCP dan mandiri secara lembaga dan keuangan, yaitu sebesar 45\%. Selanjutnya diikuti oleh program sosialisasi dan edukasi ZCP secara terus menerus dan harus ada syariah kontrol terhadap BAZNAS sebesar $29 \%$, dan yang menempati urutan terakhir untuk strategi dukungan ZCP dan sinergi organisasi pengelola zakat sebesar 25\%. Hasil perolehan nilai rater agreement seluruh responden yaitu 19\%. Hal ini menunjukan bahwa tingkat kesepakatan responden rendah.

\section{KESIMPULAN}

Secara keseluruhan dapat disimpulkan bahwa responden memiliki tingkat kesepakatan yang tinggi tentang kurangnya edukasi dan sosialisasi terkait ZCP. Pihakpihak yang terkait, dalam hal ini BAZNAS pusat diharapkan dapat segera memberi edukasi dan sosialisasi tentang ZCP kepada BAZNAS tingkat daerah. Selain itu, diharapkan pula BAZNAS nantinya akan lebih akuntabel dan transparan dalam setiap kegiatan dan laporan. BAZNAS diharapkan juga untuk bisa mandiri secara formal dan finansial tetapi juga harus ada kontrol yang dilakukan terhadap BAZNAS. Terakhir, pemerintah harus mendukung penerapan ZCP serta harus ada sinergi dan kolaborasi antar organisasi pengelola zakat dan antara organisasi pengelola zakat dengan pemerintah agar potensi zakat yang ada bisa terealisasikan demi kesejahteraan rakyat.

\section{DAFTAR PUSTAKA}

Amalia, E. (2017). The Shariah Governance Framework For Strengthening Zakat Management in Indonesia: a Critical Review of Zakat Regulations. Proceedings of $1^{\text {st }}$ International Conference of Law and Justice - Good Governance and Human Rights in Muslim Countries: Experiences and Challenges (ICLJ), 162, 133-138. https://dx.doi.org/10.2991/ iclj-17.2018.28.

Ascarya. (2005). Analytic Network Process (ANP): Pendekatan Baru Studi Kualitatif. Seminar Intern Program Magister Akuntansi Fakultas Ekonomi di Universitas Trisakti, Jakarta.

Beik, I. S. (2016, Mei 27). ZCP dan Penguatan Tata Kelola Perzakatan. Republika. Diakses dari https://republika.co.id/berita/o7soq6336/zcp-dan-penguatan-tata-kelola-perzakatan.

Beik, I. S., Hanum, H., Muljawan, D., Yumanita, D., Fiona, A., \& Nazar, J. K. (2016). Consultative Document Core Principles for Effective Zakat Supervision. Jakarta: International Working Group on Zakat Core Principles.

DEKS-BI. (2016). Pengelolaan Zakat yang Efektif: Konsep dan Praktik di Berbagai Negara. Seri Keuangan Ekonomi Syariah. Jakarta: DEKS BI dan P3EI FE UII.

Divisi Publikasi dan Jaringan. (2016). Outlook Zakat Indonesia 2017. Jakarta: Pusat Kajian Strategis Badan Amil Zakat Nasional.

Divisi Publikasi dan Jaringan. (2017). Outlook Zakat Indonesia 2018. Jakarta: Pusat Kajian Strategis Badan Amil Zakat Nasional

Divisi Riset dan Kajian. (2017). Dampak Pendayagunaan Zakat BAZNAS terhadap Kesejahteraan Mustahik di Indonesia. Jakarta: Pusat Kajian Strategis Badan Amil Zakat Nasional. 
Firdaus, M., Beik, I. S., Irawan, T., \& Juanda, B. (2012). Economic Estimation and Determinations of Zakat Potential in Indonesia. IRTI Working Paper Series No. 1433-07. Jeddah: IRTI.

Firmansyah, I., \& Sukmana, W. (2014). Analisis Problematika Zakat pada BAZNAS Kota Tasikmalaya: Pendekatan Metode Analytic Network Process (ANP). Jurnal Riset Akuntansi dan Keuangan, 2(2), 392-406. http://dx.doi.org/10.17509/jrak.v2i2.6593.

Hermawan, F. D., Saptono, R., \& Anggrainingsih, R. (2014). Modifikasi Analytic Network Process untuk Rekomendasi Pemilihan Handphone. ITSMART: Jurnal Teknologi dan Informasi, 3(2), 1-7.

Huda, N., Anggraini, D., Ali, K. M., Mardoni, Y., \& Rini, N. (2014). Prioritas Solusi Permasalahan Pengelolaan Zakat di Propinsi Banten dan Kalimantan Selatan dengan Metode AHP. AlIqtishad: Jurnal Ilmu Ekonomi Syariah, 6(2), 223-238. https://doi.org/10.15408/aiq. v6i2.1232.

Kusnadi, Surarso, B., \& Syafei, W. A. (2016). Implementasi Metode Analytic Network Processs untuk Penentuan Prioritas Penanganan Jalan Berdasarkan Tingkat Pelayanan Jalan. Jurnal Sistem Informasi Bisnis, 6(2), 105-113. DOI: 10.21456/vol6iss2pp105-113.

Rusydiana, A. S., \& Firmansyah, I. (2017). Prioritizing Zakat Core Principles Criteria. Esensi: Jurnal Bisnis dan Manajemen, 7 (2), 277-302. https://doi.org/10.15408/ess.v7i2.5275.

Saaty, R. W. (2016). Decision Making in Complex Environment: The Analytic Network Process (ANP) for Dependence and Feedback. Pittsburgh: Creative Decisions Foundations.

Siregar, S. (2016). Problematika Fundraising Zakat: Studi Kasus BAZNAS di Sumatera Utara. Miqot: Jurnal Ilmu-Ilmu Keislaman, 40(2), 247-266. DOI: http://dx.doi.org/10.30821/ miqot.v40i2.299.

Tanjung, H., \& Devi, A. (2013). Metodologi Penelitian Ekonomi Islam. Jakarta: Gramata Publishing.

Internet:

www.bi.go.id

www.bps.go.id 